\title{
Deep Drawing of a Ni-Ti Shape Memory Alloy Sheet
}

\author{
Kuang-Jau Fann ${ }^{1, a}$ and Chun-Hao Chang ${ }^{1}$ \\ ${ }^{1}$ National Chung Hsing University, Department of Mechanical Engineering, 402 Taichung, Taiwan, R.O.C
}

\begin{abstract}
This study is aimed to investigate the properties of Ni-rich Ni-Ti shape memory alloy sheet parts during and after deep drawing process at room temperature, in which the metal is under plane tension-compression stress state. After annealing at different elevated temperature, shape memory alloy sheet is formed at room temperature by a circular cylindrical punch in different forming depths. Thereafter the deep drawn sheet part is subjected to aging for shape memory treatment. A free shape recovery test is further conducted onto the deep drawn shape memory alloy sheet part. As a result, the sheet metal has austenitic phase at room temperature, which shows superelasticity. Too small forming amount causes severe springback and the form of the deep drawn sheet part is very hard to detect with the naked eye. Only if a forming amount greater than or equal to $4 \mathrm{~mm}$ is applied, a form can be achieved on to the sheet part. The subsequent aging shape memory treatment can induce further springback of the deep drawn sheet part. The higher the temperature of the previous annealing, the less the springback by aging. The free shape recovery test shows that the deep drawn sheet part only undergoing annealing without shape memory treatment still possesses shape memory effect. Nevertheless, the deep drawn sheet part aged for shape memory can show a better shape recovery.
\end{abstract}

\section{Introduction}

It was found in 1963 that equiatomic Ni-Ti alloys carry shape memory effect in association with superelasticity [1]. The shape memory effect shows that after severe deformation the alloy can recover its original shape prior to the deformation by raising its temperature [2]. It is caused by phase transformation between austenite at high temperature and martensite at low temperature [3], while superelasticity is a similar behaviour when the material undergoes those phase transformations during the elastic deformation between loading and unloading [4]. The Ni$\mathrm{Ti}$ alloys are the most widely used shape memory alloy because of their excellent mechanical properties, distinguished corrosion inhibition, brilliant wear resistance, and perfect biocompatibility $[5,6]$. The application of Ni-Ti shape memory alloy is primarily made of tube or wire, particularly because the alloy does not have good processing and machining characteristics. It is often made by plastic forming [7]. However the Ni$\mathrm{Ti}$ shape memory alloy has the superelastic property at room temperature, making it easy to springback to its original shape, so that the thermomechanical processing technology is usually applied [8], in that the alloys are formed with a pair of dies in hot state. To develop the shape memory effect, the alloys and the dies are then kept in a constraint state inside a furnace and followed by aging treatment. However, this process demands large volume of dies in an extraordinary quality showing good resistance to high temperature, which results in huge cost of dies and equipment. Furthermore, sheet metal forming

\footnotetext{
${ }^{a}$ Corresponding author: author@e-mail.org
}

process, which is broadly used in mass production, is distinctly operated in cold because of geometry and heat transfer characteristic of metal sheets. These two hurdles result in the application of $\mathrm{Ni}-\mathrm{Ti}$ shape memory alloy being limited to the tube or wire as raw material. Fann and Huang [9] have developed a cold forming process for $\mathrm{Ni}$-Ti shape memory alloy wires to eliminate the use of expensive die sets, not only in the forming, but also in the constraint aging process at elevated temperature, which can help to extend the application of Ni-Ti shape memory alloys to the sheet forming process. However, the stress state appearing in sheet metal forming is a plane stress state, which is different to the wire bending process. This study is thus aimed to investigate the feasibility of the processes for shape memory alloy sheet part, cold forming with only one die set and aging without any further die set, and to investigate the shape memory effect of Ni-Ti shape memory alloy sheets during and after deep drawing process, which is under plane tensioncompression stress state.

\section{Setups}

Ni-rich Ni-Ti shape memory alloy sheets having a thickness of $0.8 \mathrm{~mm}$ were commercially acquired from a local manufacturer (Zhongrui Material Technology Corp., Taiwan). After waterjet cutting the alloy sheets into circular shapes with a diameter of $36 \mathrm{~mm}$, the blank sheets are annealed at different temperatures, $650^{\circ} \mathrm{C}$ $750^{\circ} \mathrm{C}$, and $850^{\circ} \mathrm{C}$, respectively, for one hour and 
thereafter cooled in the furnace until it reaches $400^{\circ} \mathrm{C}$ and taken out for cooling in the air to the room temperature.

The metal sheet blank was put onto the bottom die without further surface treatment and any lubrication. The metal sheet blank was then clamped by the blankholder with four bolts. Each was preloaded by four stacks of disc springs between the blankholder and the flange, as shown in Figure 1. The bottom die had a corner radius of 2.5 $\mathrm{mm}$ and the four bolts could provide a $680 \mathrm{~N}$ blankholder force on to the sheet blank, which was determined according the handbook [10]. The whole die set was then mounted on the test bench, which was a universal material test machine driven by a servo motor. The cylindrical punch in a diameter of $20 \mathrm{~mm}$ having a corner radius of $4 \mathrm{~mm}$ was then installed on to the cross head of the test machine. The approaching speed of the punch to the blank was set as $6 \mathrm{~mm} / \mathrm{min}$.

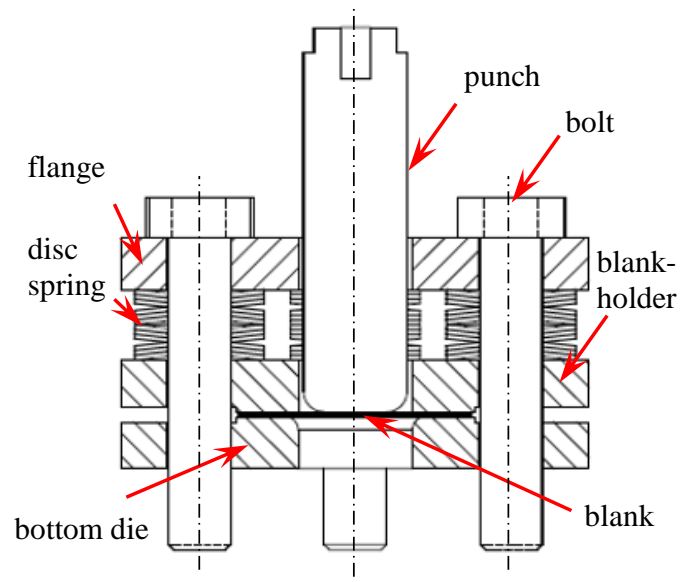

Figure 1. Sectional view of experiment setup (die set).

Because the experiment was conducted at room temperature, at which the material used in this study was at a state in the stable austenite phase, the sheet blank possessed superelasticity. It could be expected that there would be considerable springback after deep drawing process. For this purpose, the springback rate $p$ was defined as a ratio of the variation of the height $\Delta h$ of the axis center of the sheet part between the down stroke and the up stroke of the punch during the deep drawing process to the forming depth $s$. Namely,

$$
p=\Delta h / s \times 100 \%
$$

\section{Results and Discussion}

A simulation of deep drawing Ni-Ti shape memory alloy sheets had been conducted with the commercial finite element software DEFORM 2D [11] under elastic-plastic deformation, because the formulation for an elasticsuperelastic constitution is similar to elastic-plastic one [12]. The stress-strain relation used in the previous study [13] on stretch forming, in which the material had a Young's modulus of $41 \mathrm{GPa}$ with a plateau strength of about $530 \mathrm{MPa}$ and a tangent modulus of 1,286 $\mathrm{MPa}$ during loading and $21 \mathrm{GPa}$ during unloading after a $12 \%$ strain, was applied to this study as well.
Figure 2 shows the load over the stroke of the punch. It can be observed that all the deformation made by a punch stroke or a forming depth of $2 \mathrm{~mm}$ (solid blue line) sprung completely back as the punch load fully vanished and the punch just returned to its starting position (stroke $0 \mathrm{~mm}$, lower curve). As the deep drawing process was performed by a forming depth of $4 \mathrm{~mm}$ (solid green line), the punch was at the stroke of $2.69 \mathrm{~mm}$ from its starting position at the time that the punch load disappeared. The height of the formed part had a springback of $1.31 \mathrm{~mm}$ In case of a forming depth in $6 \mathrm{~mm}$ (solid red line), the springback of the formed part was only $1.09 \mathrm{~mm}$. It seems that the more the stroke applied, the deeper the forming depth, the lower the springback. It can be attributed to that the shape of formed cup might lead to the material not easily to springback.

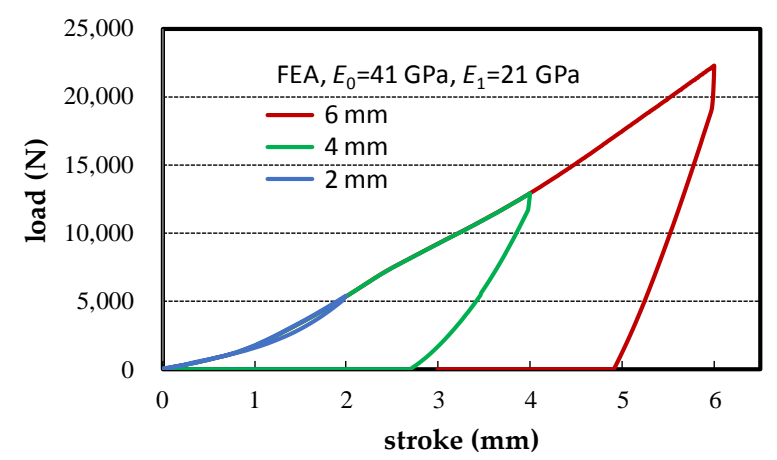

Figure 2. Punch load over stroke of deep drawing Ni-Ti shape memory alloy sheet determined by finite element analysis.

Figure 3 shows the above mentioned formed parts before unloading (dashed green line) at the bottom dead center and after unloading (solid red line) in comparison with the original blank sheet shape (dashed blue line).

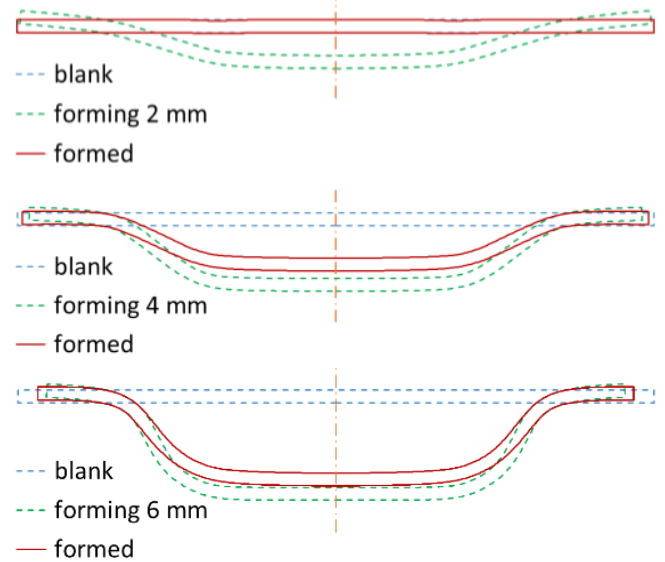

Figure 3. Sectional view of the blank (dashed blue line) and the part at the bottom dead center of the punch (dashed green line) and after unloading (solid red line) obtained from a finite element analysis of deep drawing Ni-Ti shape memory alloy sheet with a forming depth of (a) $2 \mathrm{~mm}$, (b) $4 \mathrm{~mm}$, and (c) $6 \mathrm{~mm}$.

It can be seen that there is almost no difference between the formed part after deep drawing with a forming depth of $2 \mathrm{~mm}$ (Figure 3 (a)) and the original blank sheet. The only one variation is located around the radius corner of the punch, where an indistinguishable 
about $0.05 \mathrm{~mm}$ deformation can be exposed. Furthermore, the distance between the bottom die and the blankholder is not equal to the thickness of the blank sheet, while the punch reaches its bottom dead center, so that the deformation of the blank sheet is not thoroughly as expected. According to the equation (1), the springback rate for this case is $97.4 \%$.

If the forming depth is extended to $4 \mathrm{~mm}$ as shown in Figure 3 (b), the height difference at the axis center of the part obtained at the punch bottom dead center and after unloading is $1.26 \mathrm{~mm}$, which deviates from $1.31 \mathrm{~mm}$ obtained with load stroke curve (Figure 2). It might be associated to that the latter only considers the contact condition between the tools and the blank sheet, while the former counts all the deformation on the blank sheet. If the deformation on the outer ring of the flange is considered as well, the springback is then $1.37 \mathrm{~mm}$ and the springback rate is thus $34.2 \%$, which is distinctly reduced in comparison to the forming depth of $2 \mathrm{~mm}$.

When the forming depth is increased to $6 \mathrm{~mm}$, the height at the axis center of the sheet part has its maximum either at the bottom dead center of the punch stroke or after unloading the punch. The difference of these depths is then $0.89 \mathrm{~mm}$. If the deformation on the outer ring of the flange is regarded as well, the springback is as large as $1.09 \mathrm{~mm}$, which is the same as the result obtained from the load stroke curve (Figure 2). The springback rate is further turned down to $27.2 \%$. If more attention is paid on the outer ring of the flange, it can be noticed that the diameter of the outer ring is extended from $32.72 \mathrm{~mm}$ at the bottom dead center of the punch stroke to $33.75 \mathrm{~mm}$ after unloading, totally 1.03 $\mathrm{mm}$, which is larger than that observed from the smaller punch strokes.

If the observation of the aforementioned distance between the blankholder and the lower die is moved onto the stroke of the press plate, the result of Figure 4 can be obtained, wherein the stroke shown in the ordinate refers to the upward movement of the blankholder forced by the deformation of the blank flange during deep drawing the blank sheet. It can be seen that the first $2 \mathrm{~mm}$ of the punch stroke the blankholder keeps rising until its stroke reaches $0.54 \mathrm{~mm}$. It means that it is obvious that the preload of the blankholder, $680 \mathrm{~N}$, is not enough to keep the blankholder at its bottom dead center. Thereafter, during the subsequent deep drawing stroke, the stroke of the blankholder begins to decrease. This might be due to the continuous reduction in the area of the flange part, which results in an increase in the average pressure on the blankholder, which in turn causes the flange part to press down and the blankholder stroke to decrease. When the punch stroke is at $4.8 \mathrm{~mm}$ (at time $48 \mathrm{~s}$ ), the blankholder stroke begins to rise again. This might be due to the fact that the blankholder on the flanges needs more load because of strain hardening. However, the blankholder force was set as a constant, so that the blankholder rises again.

Figure 5 shows the deep drawn parts from the sheet blank annealed at different temperatures and formed at different depths. It can be seen that there is still an oxide layer remaining visible on the surface of the sheet after the annealing process and that the larger the forming depth, the more obvious the shape of the deep drawing. That means that the higher the side wall formed, the smaller the springback, and the higher the dimensional accuracy. At the forming depth of $2 \mathrm{~mm}$, the formed shape is almost completely sprung back. Although it is hard to directly convert the area change on the formed part with the depth of $2 \mathrm{~mm}$ to the strain, it can be explained by the strain distribution shown in Figure 6 along with the stress-strain curve mentioned above that all deformation will completely springback after the force is released if the strain is below $1 \%$. If the average strain is about $5 \%$, which is in the early stage of the plateau region, such deformation is likely to springback with superelasticity, so that the residual plastic deformation is not easy to see. For the part formed with a depth of $4 \mathrm{~mm}$, its strain around the punch corner has exceeded $10 \%$, which is in the late stage in the plateau region, so that there should be more plastic deformation on the part and the superelastic area is then contracted. Therefore, the springback is reduced and a noticeable formed shape can be seen. For the part formed with the depth of $6 \mathrm{~mm}$, the average strain on the sidewall is more than $10 \%$, so that the whole formed region is full plastically deformed. A springback caused by superelastic deformation does almost not exist and the formed shape is extremely clear.

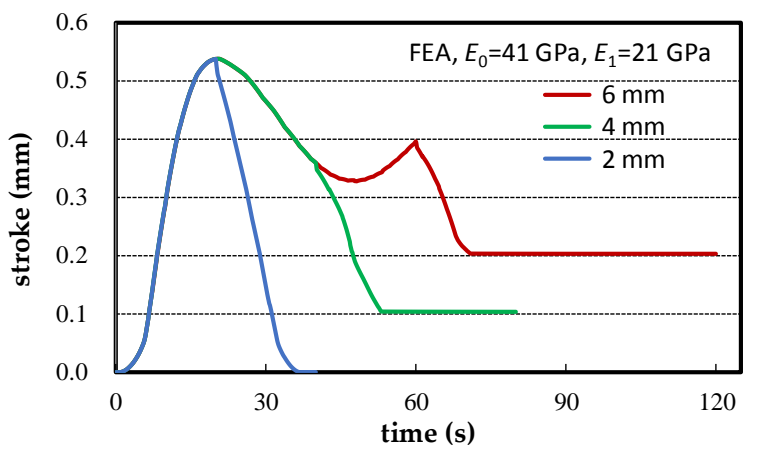

Figure 4. Stroke evolution of the blankholder obtained from a finite element analysis of deep drawing a Ni-Ti shape memory alloy sheet.

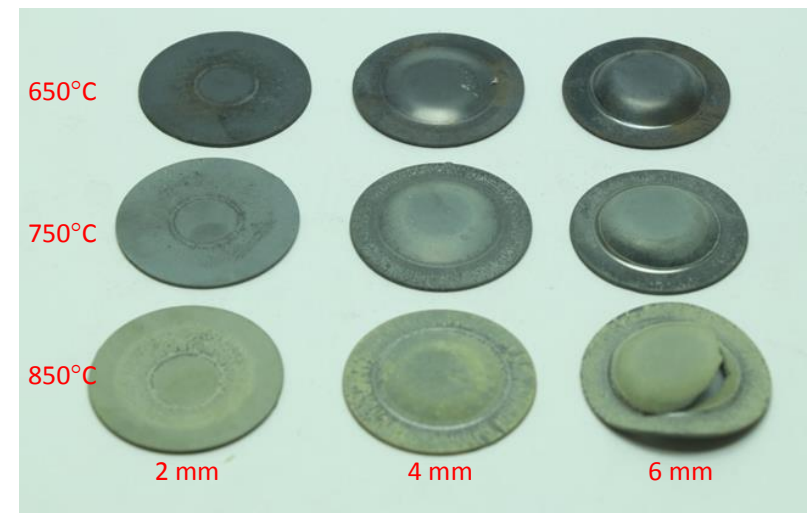

Figure 5. Parts of Ni-Ti shape memory alloy sheet annealed at different temperatures and formed in diverse depths.

The above-mentioned formed parts were placed in a furnace treated at $300^{\circ} \mathrm{C}$ for one hour as recommended in [9], and water quenched thereafter. This precipitation or aging served as a shape memory treatment. However, after the shape memory treatment, the residual stress 
generated by the cold forming on the sheet parts was then eliminated, and the parts sprung back further, which caused the height at the axis center to fall again. Figure 7 shows the height at the axis center of the parts after deep drawing with a depth of $4 \mathrm{~mm}$ and after shape memory treatment.

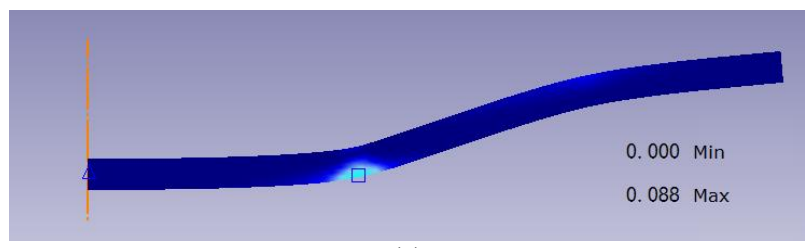

(a)

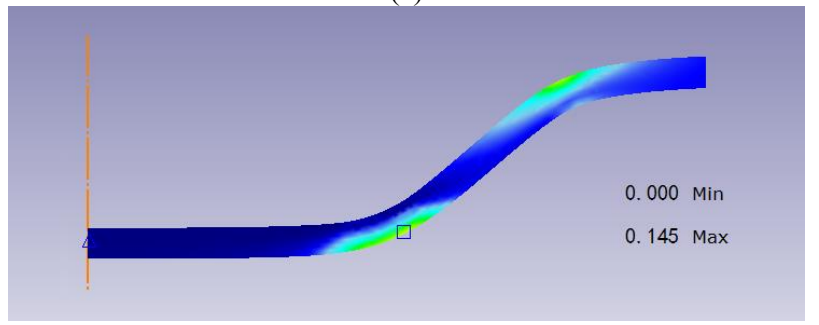

(b)

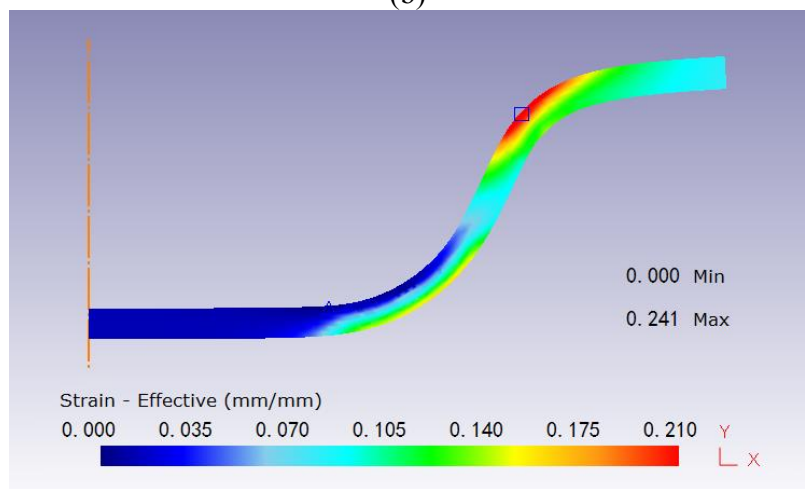

(c)

Figure 6. Strain distribution of the part at the punch bottom dead center obtained from FEA of deep drawing Ni-Ti shape memory alloy sheet with a forming depth of (a) $2 \mathrm{~mm}$, (b) $4 \mathrm{~mm}$, and (c) $6 \mathrm{~mm}$.

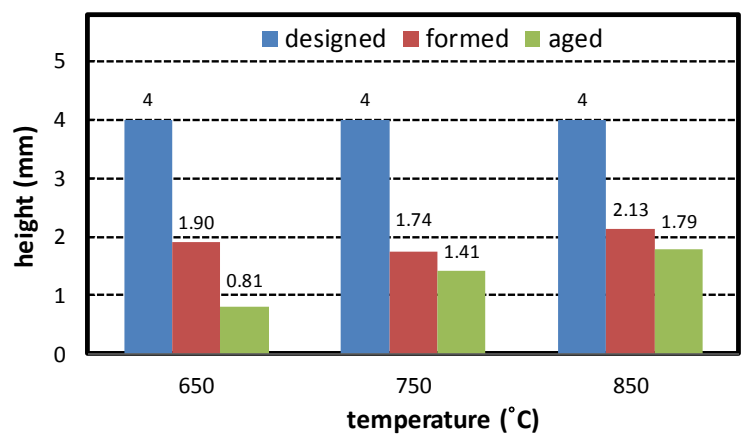

Figure 7. Height at the axis center in parts of Ni-Ti shape memory alloy sheet annealed at different temperatures after forming with depth of $4 \mathrm{~mm}$ and after shape memory treatment.

The height shown in blue bar is the forming depth, and the red bar shows the average height from the four deep drawing experiments. The green bar shows the average height of the two parts measured after shape memory treatment. It can be seen that the aging treatment would create a considerable springback, particularly for the sheet annealed at $650^{\circ} \mathrm{C}$, in which the shape memory treatment caused a springback rate is as high as $57.4 \%$ (calculated from $1-0.81 / 1.90$ ). It might be attributed to that the annealing temperature $650^{\circ} \mathrm{C}$ did not exceed the solvus. There was no solid solution effect activated, which caused in turn that the subsequent treatment at $300^{\circ} \mathrm{C}$ had no aging effect. The subsequent treatment could only be regarded as an annealing treatment after a cold deep drawing process, so that the cold work characteristics disappear and the formed height was lost further. For the sheets annealed at $750^{\circ} \mathrm{C}$ and at $850^{\circ} \mathrm{C}$, the springback rate after aging $(19.2 \%$ and $16.1 \%$, respectively) is much lower than that after forming (56.5\% and $46.8 \%$, respectively). It is obvious that although the annealing followed by furnace cooling and air cooling is different from the solid solution treatment, which is followed by water quench, there is still an aging effect, so that the original cold formed shape is not easily lost.

The formed part was placed between the two plates and afterwards $95 \%$ ethanol soaked with dry ice, showing a temperature of $-70 \pm 2^{\circ} \mathrm{C}$, was injected there between, so that the Ni-Ti shape memory alloy is indeed in martensitic phase. Applying force to the two plates to let the part back into a flat shape and to maintain the state for more than 30 seconds, the flat part was taken out and gradually returned to room temperature from low temperature and its shape came back to the formed cup shape. Because there was no any external force involved, it is called free recovery.

The principle of the shape memory effect and its free recovery test is that the shape memory alloy part is first subjected to aging at a high temperature (room temperature for this study) in austenitic phase for shape memory and then its temperature drops to a low temperature (for this study, a 95\% ethanol environment impregnated with dry ice) having martensitic phase in a crystal lattice of twin, but the shape obtained at the high temperature remains. At this low temperature, applying a load on the part, the part will be deformed by changing the crystal lattice structure in the way of de-twinning. When the load is removed, the de-twinned crystal lattice does not return to the twin form and keeps the deformed shape. This is also the reason why the part in the aforementioned test maintains its flat state after removing the clamping plates at a low temperature. Once the temperature rises to a high temperature, the internal stress of the de-twinned crystal lattice is released and the twin crystal lattice is restored for the martensitic phase. At the same time, as temperature rises, the austenitic phase is converted from the martensitic phase and the previous part shape obtained at the high temperature is then restored.

If the height at the axis center of the part before the shape recovery test $\mathrm{h} 1$ is compared with that after the test $\mathrm{h} 0$, the shape recovery rate $\mathrm{r}$ is then defined as follows.

$$
r=h_{1} / h_{0} \times 100 \%
$$

For different forming depth, the shape recovery rate can be calculated from the experiment results and plotted in a bar graph, as shown in Figure 8. 
The shape recovery rate shown in red bar is taken from the recovery test, which was conducted directly with the part just formed with a depth of $4 \mathrm{~mm}$ without further aging shape memory treatment, while the green bar shows the result of the recovery test from the part after shape memory treatment. It is obvious that the shape recovery rate of the formed part without shape memory treatment is not as good as that with the shape memory treatment. However, the shape recovery rates are similar and show that the formed part without shape memory treatment has an excellent shape recovery ability. The higher the annealing temperature, the higher the shape recovery rate, regardless whether the part was aged for shape memory or not.

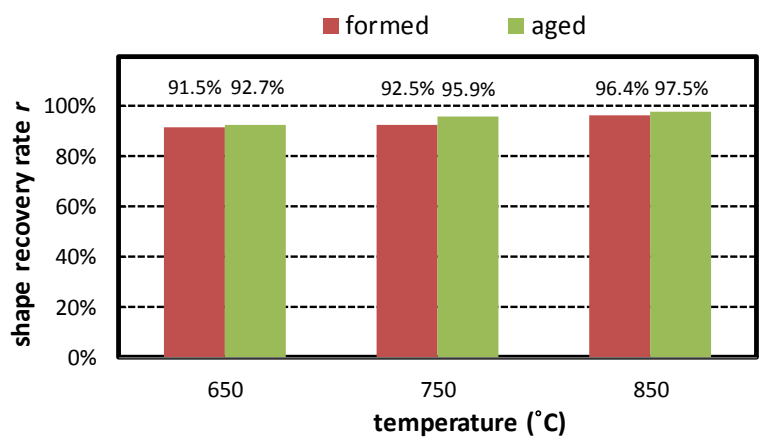

Figure 8. Free recovery rate determined from parts of $\mathrm{Ni}-\mathrm{Ti}$ shape memory alloy sheet annealed at different temperatures after forming with depth of $4 \mathrm{~mm}$ and after shape memory treatment.

\section{Conclusions}

This study attempted to investigate how Ni-rich $\mathrm{Ni}$ - $\mathrm{Ti}$ shape memory alloy sheet deforms during a deep drawing process and how is the shape memory effect of the deep drawn part. Ni-rich Ni-Ti shape memory alloy sheets having a circular shape in a diameter of $36 \mathrm{~mm}$, annealed at $650^{\circ} \mathrm{C}, 750^{\circ} \mathrm{C}$ and $850^{\circ} \mathrm{C}$, respectively, have been drawn with depths of $2 \mathrm{~mm}, 4 \mathrm{~mm}$, and $6 \mathrm{~mm}$, respectively. It is followed with an aging process at $300^{\circ} \mathrm{C}$ as a shape memory treatment, and a shape recovery test is thereafter conducted. The material shows its austenitic phase at room temperature, while it shows its martensitic phase in an ethanol environment impregnated with dry ice.

The experiment results show that the higher the forming depth, the higher the deformation and the smaller the springback rate. The formed part with a drawing depth of $2 \mathrm{~mm}$ has a small amount of deformation, and the springback rate is nearly $100 \%$, so that it is hard to see the formed shape. But the formed parts with a drawing depth of $4 \mathrm{~mm}$ and $6 \mathrm{~mm}$ have a higher deformation, so that the springback rate is also less than $50 \%$ and the parts have a distinct formed shape.

When the formed part is subjected to aging shape memory treatment, it will springback further. The higher the annealing temperature before forming, the smaller the springback during the aging heat treatment, but this springback rate is at least $16 \%$.
The shape recovery test shows that the deep drawn sheet part without the aging shape memory treatment still has the shape recovery ability, and its shape recovery rate is a little smaller than that with the aging shape memory treatment but at least more than $90 \%$. The higher the annealing temperature, the higher the shape recovery rate, regardless whether the part was aged for shape memory or not.

\section{Acknowledgements}

The authors would like to acknowledge that this study was financially supported by the Ministry of Science and Technology of the Republic of China with the grant MOST 104-2221-E-005-022.

\section{References}

1. W.J. Buehler, J.V. Gilfrich, R.C. Wiley, J. Appl. Phys., 34, 1475 (1963)

2. A. Ölander, Z. Krist., 83A, 145 (1932)

3. L.C. Chang, T.A. Read, T. Metall. Soc. AIME J. Metals, 189, 47 (1951)

4. J.W. Christian, The Theory of Transformations in Metals and Alloys (J.W. Christian, Elsevier, Oxford, UK, 1965) 1102

5. C.M. Wayman, T.W. Duerig, Engineering Aspects of Shape Memory Alloys (T.W. Duerig, K.N. Melton, D. Stöckel, C.M. Wayman, Butterworth-Heinemann, London, UK, 1990) 3

6. T. Duerig, A. Pelton, D. Stöckel, Mater. Sci. Eng., A273-275, 149 (1999)

7. M.H. Wu, Mater. Sci. Forum, 394-395, 285 (2002)

8. K.-J. Fann, H.-C. Hsu, Adv. Mater. Res., 939, 430 (2014)

9. K.-J. Fann, P.-M. Huang, Key Eng. Mater., 661, 98 (2015)

10. H. Tschätsch, Metal Forming Practise Processes Machines - Tools (Springer, Berlin, Germany, 2006)

11. X. Gao, W. Huang, J. Zhu, IUTAM Symposium on Smart Structures and Structronic Systems (U. Gabbert, H.S. Tzou, Kluwer Academic Publishers, Dordrecht, The Netherlands, 2001) 137

12. J. Fluhrer, Deform 2D Version 8.1 User's Manual (Scientific Forming Technologies Corporation, Columbus, Ohio, USA. 2004)

13. K.-J. Fann, J.-Y. Su, IOP Conf. Ser.: Mater. Sci. Eng., 317, 012079 (2018) 